\title{
THE COLOGNE MEETING OF THE DEUTSCHE MATHEMATIKER-VEREINIGUNG.
}

THE eightieth convention of German naturalists and physicians was held at Cologne, September 20-26, 1908. Mathematics and astronomy together formed one of the thirty-one sections. The total attendance was about two thousand, of which the Deutsche Mathematiker-Vereinigung as a sub-division claimed nearly one hundred.

On the evening of September 20, an informal reception was given in the Bürgergesellschaft. A general session of all the divisions took place in the Gürzenich on the following morning. After greetings from representatives of the administration and from various societies in Cologne, two papers were read: (1) The achievements and influence of Albertus Magnus (one of the founders of the ancient Cologne University); (2) Motor balloons and flying machines.

The sessions of the Vereinigung were held in the HandelsHochschule. Under the influence of President Klein, the society devoted the meetings largely to the problems of applied mathematics, thus acting as mentor for the Naturforscherversammlung. The following papers were read:

1. H. Mrnkowski, Göttingen, "Space and time."

2. G. HAMEL, Brünn, "The foundations of mechanics."

3. E. H. Timending, Strassburg, "The historical development of the concept of force."

4. P. Stä Ckel, Karlsruhe, "Remarkable motions of the top."

5. R. v. Mises, Brünn, " Problems of technical hydromechanics."

6. F. MüLLER, Dresden, "Plans for the publication of the works of Leonhard Euler."

7. H. Wiener, Darmstadt, "On the geometry of the binary forms."

8. H. Jung, Marburg, "Algebraic functions of two independent variables."

9. H. Reissner, Aachen, "Scientific problems in the mechanics of flight."

Number 8 has already appeared in the Comptes Rendus; numbers 2 and 4 will soon be published in the Mathematische Annalen, and number 5 in the Physikalische Zeitschrift. Ab- 
stracts of the other papers are given below, the numbers corresponding to those in the list above.

1. Professor Minkowski discussed the complete revolution that has taken place in our conception of time and space, owing to the exact mathematical deductions from the latest investigations of physics. Lagrange has called physics a four-dimensional geometry because three dimensions of space, and one of time are introduced, and this definition seems to-day to be applicable in a deeper, unhoped-for sense. Minkowski shows that the remarkable hypothesis of $H$. A. Lorentz concerning the contraction of the electrons and the alleged contradiction between the newtonian mechanics and the modern theory of electricity can be completely accounted for if we assume that we live in a four-dimensional world of which the fourth dimension (time) may be neglected with a certain amount of freedom. The axiom that the velocity of matter cannot exceed that of light in ether plays here an important role. This new comprehension of the world as a sort of union of time and space makes possible great strides in the theory of electricity and magnetism, and requires finally a revision of all physical theories. That these revisions are capable of being carried out is due alone to the many-sided advances made by pure mathematics in the past century.

3. Professor Timerding's paper was an historical review of the mathematical conception of force with especial reference to the notions of Newton.

6. Professor Müller sketched the career and influence of Euler and outlined the plans that are being made for the publication of his works.

7. Professor. Wiener continued his investigations in the geometric interpretation of binary forms, making use of polarity and reflection.

9. There are three chief properties of a flying machine, the capability of floating, the stability, and the power. The simplest cases of the first can be solved by theoretical hydrodynamics, but the more difficult must be experimentally determined. The problem of the most favorable shape of the planes and the most advantageous angle of motion has not been systematically treated since the time of Lilienthal, and our knowl- 
edge regarding the position of the resulting pressure is very incomplete. It is shown that the problem of stability must be treated as a case of oscillation about a state of stationary motion. The vibration in the plane of motion may be regarded as consisting of two components, of which one however is so damped that it does not come into practical computation. In a machine consisting of parallel surfaces the presence of horizontal tail surfaces aids in lessening the oscillation, but they are not economical when the power comes into consideration. Models are not helpful in stability experiments because the theory of dimensions is not applicable. A strictly hydrodynamical treatment of the propeller problem is not at present possible, but the application of the laws of oblique motion of thin plates produces a good propeller. Professor Reissner has found also that the propeller which he constructed in accordance with his solution of the problem by means of the calculus of variations works to good advantage, and his researches in cooperation with Professor Junkus are to be continued on a larger scale.

The business session of the Deutsche Mathematiker-Vereinigung was held on the afternoon of the 22nd. The report showed that the present membership is about seven hundred. The executive committee for the year 1908-09 is as follows: M. Krause, president ; A. Krazer, secretary ; A. Ackermann-Teubner, treasurer ; A. Gutzmer, editor of the Jahresbericht; A. Schönflies, F. Klein, F. Engel, and F. Schur. As German representatives in the international committee on mathematical instruction to report to the congress in Cambridge (1912), F. Klein and P. Treutlein were chosen. The society voted the sum of five thousand francs in aid of the publication of the works of Euler undertaken by the Swiss scientific societies.

Professors Bolza, of Chicago, Field, of Michigan, and Richardson, of Brown were the only Americans present. On the evening of the 21 st the visitors were entertained in the zoological gardens by the scientific societies of Cologne, and on the following evening a banquet was held in the Gürzenich. On Wednesday evening the theatre and opera gave special performances to which the members were invited. The reception given by the city took place on Thursday evening, and on Saturday four excursions to various points of interest in the vicinity of Cologne were arranged. The next meeting will be held in Königsberg.

R. G. D. RichaRdSON. 